\title{
Low-Density Steels
}

\author{
RADHAKANTA RANA ${ }^{1,2,3,4}$ \\ 1.-Tata Steel Europe, Wenckebachstraat 1, 1970CA IJmuiden, The Netherlands. 2.-Present \\ address: Advanced Steel Processing and Products Research Center, The George S. Ansell Depa- \\ rtment of Metallurgical and Materials Engineering, Colorado School of Mines, Golden, CO 80401, \\ USA. 3.—e-mail: radrana@mines.edu. 4.—e-mail: rana9433@gmail.com
}

Reducing the weight of an engineering structure saves both material and energy, and it is therefore considered desirable provided other design considerations are satisfied. To achieve this goal, light metals such as aluminum, magnesium, titanium, and their alloys are brought into consideration in preference to steels. On the other hand, as engineered materials produced and used, steels account for a very high volume in the world. One of the key industrial domains, viz. the automotive sector, finds extensive use of steels because of their excellent combination of strength, formability, recyclability, and above all, affordability. However, unfortunately, due to their high density $\left(7.85 \mathrm{~g} \mathrm{~cm}^{-3}\right.$ for ferrite and $8.15 \mathrm{~g} \mathrm{~cm}^{-3}$ for austenite), steels are not so effective in light-weighting of automotive structures, although as a result of increased strength, newer designs have succeeded in reducing the weight of the auto body and other components. A comparison of strength and density of steels vis-àvis those of other engineering materials, including other metals, is shown in Fig. $1{ }^{1}$ The comparatively higher strength allows use of smaller dimensions of components made of steels, but considerations of stiffness and structural rigidity restrict the downgauging potential. ${ }^{2}$

Furthermore, even though automobiles account for a major portion of the economy in the advanced world (e.g. 3-3.5\% of gross domestic product in the USA) ${ }^{3}$ they are also one of the largest sources of greenhouse gas emissions in the world attracting stringent environmental regulations. ${ }^{4}$ These circumstances compel the automotive manufacturers to continuously look for potential avenues that could reduce emissions. Lowering the density of steels is therefore considered an effective approach in this endeavor that would allow use of a thicker gauge in automobiles for stiffness, while leading to greater fuel efficiency and reducing emissions.

Radhakanta Rana is the Guest Editor of the special topic of "Low-Density Steels".
The first information on "low-density steels" dates back to as early as the 1930 s with Korter and Ton ${ }^{5}$ reporting on the use of the Fe-Mn-Al-C system for the first time. Subsequently, in the 1950s, Ham and Carin ${ }^{6}$ dwelt on the possibility of replacing costly $\mathrm{Ni}$ and $\mathrm{Cr}$ in stainless steels by cheaper $\mathrm{Mn}$ and $\mathrm{Al}$, respectively, and in the process bringing about advantage in the density too. During the 1980s and 1990 s, Fe-based aluminides $\left(\mathrm{FeAl}\right.$ and $\left.\mathrm{Fe}_{3} \mathrm{Al}\right)$ were researched thoroughly ${ }^{7-10}$ as less expensive replacements for stainless steels and $\mathrm{Ni}$-based superalloys, while work in earlier mentioned substitution of $\mathrm{Ni}$ and $\mathrm{Cr}$ in stainless steels continued. ${ }^{11,12}$ However, serious efforts on understanding and developing low-density steels in the context of automotive applications have been seen only recently. Academic as well as industrial interest in this area is reflected by a recent publication of a "viewpoint set" in Scripta Materialia ${ }^{13}$ and by a number of patents taken out by steel companies. ${ }^{14}$

It is in the above backdrop that work on the present topic was undertaken. Although several approaches could be considered for light-weighting from a materials perspective, such as steel-matrix composites, steel foams, steel-based laminates, etc., the present compilation of articles focuses only on the bulk ferrous alloys that are less expensive and are amenable to mass production. These bulk iron alloys rely primarily on alloying with a high amount of aluminum, considering its high solubility in iron and effectiveness in reducing the density of iron. ${ }^{14}$ However, since the Fe-Al intermetallic alloys have been well documented in the past, ${ }^{7-10}$ and have not responded favorably to bulk ductilization after extensive work by several groups, they are also excluded from the scope of this special topic, which primarily focuses on the solid solution-iron alloys. As will be observed later, a good balance has been maintained in the compilation between overview and review articles and original contributions by academic as well as industrial colleagues from around the globe. The articles deal with a host of 


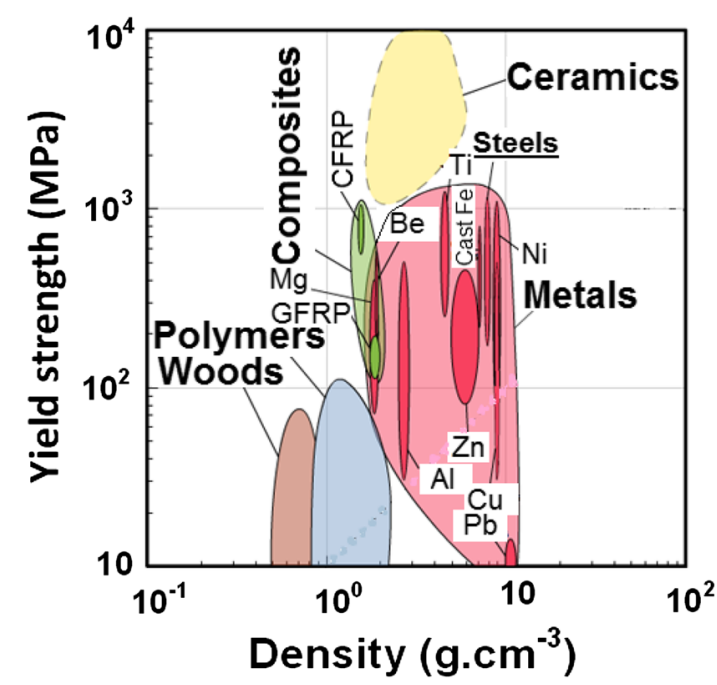

Fig. 1. Comparison of yield strength and density of steels with those of some other engineering materials. ${ }^{1}$ The symbols of metals include their alloys as well. CFRP and GFRP stand for carbon fiber-reinforced and glass fiber-reinforced polymer, respectively.

areas such as fundamentals of processing, phase transformations and microstructure development, deformation characteristics and mechanisms of strengthening, effects of alloying elements, thermodynamics of high Al-containing steels, and alloy development. A list of the articles published under the current special topic can be found at the end of this commentary; highlights from each of the articles are presented below.

\section{HIGHLIGHTS OF THE CONTRIBUTIONS}

The article by Rana et al. sets the tone of the article series by providing a comprehensive overview of the different strategies for light-weighting of ferrous materials and presenting, briefly, the physical metallurgy of bulk iron alloys. These low-density steels (Fe-Al and Fe-Mn-Al-C alloys) can be ferritic, austenitic, duplex, or triplex alloys depending on the phase constitution, and the same alloys can exhibit precipitation strengthening, strain aging, or various plasticity effects such as transformation-induced plasticity (TRIP), twinninginduced plasticity (TWIP), shear-band-induced plasticity (SIP), and micro-band-induced plasticity (MBIP). It is shown that even with a reduced Young's modulus due to high $\mathrm{Al}$ addition, in a stiffness-dominated situation, low-density steels can still result in weight saving in comparison with high-strength, low-alloy (HSLA) steels.

The fact that $\mathrm{Al}$ is actually an "old" alloying element in steels but was not looked into in the past as a density-reducing element has been underlined with some historical perspective in the review prepared by Zuazo et al. Among others, prediction of phase diagrams on $\mathrm{Al}$ addition in the $\mathrm{Fe}-\mathrm{C}$ system using CALPHAD led to new thermodynamic database that would provide a better insight into the evolution of complex microstructures in low-density steels.

A review of the past work on Fe-Mn-Al-C alloys carried out at Pohang Steel Company (POSCO) and Pohang Institute of Science and Technology (POSTECH), both in South Korea, can be found in the article authored by Sohn et al. They have reported on a thermodynamics-based alloy design, throughprocess microstructural evolution, and tensile properties of Al-rich and Mn-lean duplex low-density steels. Austenite, nucleated from fine and broken $\kappa$-carbides, possessed high mechanical stability causing a very high yield ratio. The enhanced ductility of these duplex low-density steels at similar strength levels of conventional automotive steels is indeed advantageous.

The metallurgy and current progress on $\delta$-TRIP steels, which are believed to have about 5\% lower density due to their elevated $\mathrm{Al}$ addition (>2 wt.\%), have been presented by Yi. The key aspect in $\delta$-TRIP steels is obviously the strategies of retention of $\delta$-ferrite at room temperature after casting, rolling, and welding. A high fraction of austenite can be retained in these steels at ambient temperature causing attractive mechanical properties through TRIP effect. Furthermore, $\delta$-TRIP steels exhibit excellent spot weldability and less sensitivity to formation of adherent oxides.

Bartlett and Van Aken have looked into the effects of alloying elements $\mathrm{Si}$ and $\mathrm{P}$ on the mechanical properties of austenitic cast steels containing 30Mn-9Al (wt.\%) developed for military and transportation applications. Mechanical properties equivalent to the levels of Cr-Mo steels, with a density reduced by $15 \%$, can be achieved in these steels by employing proper processing conditions. Although $\mathrm{Si}$ improves the tensile strength by increasing the kinetics of $\kappa$-carbide precipitation without deterioration in energy absorption capability when added in small quantity, $\mathrm{P}$ has proved to be detrimental with respect to toughness.

Melting/casting, liquid metal characteristics, and workability are important domains determining the manufacturability of low-density steels. Understanding of these aspects has been advanced by Satya Prasad et al., Lee and Lee, and Sunil Kumar et al. A simple air induction melting technique with flux cover (AIMFC) was shown, by Satya Prasad et al., to be an effective route for producing clean and sound ingots of low $\mathrm{C}, \mathrm{Fe}-\mathrm{Al}$ disordered alloys with mechanical properties comparable with those of costly vacuum induction melted steels. However, the $\mathrm{Al}$ content of the alloys need to be limited to a maximum of $7 \mathrm{wt} \%$, possibly to avoid preordering from taking place. Low $\mathrm{C}, \mathrm{Fe}-7 \mathrm{wt}$.\%Al alloy produced by AIMFC was demonstrated to be free from hydrogen gas porosity resulting in no formation of micro-cracks during hot rolling, and the steel could even be easily cold rolled to foil thickness without any issues. However, the width of the foils was limited to only about $2 \mathrm{~cm}$. 
Lee and Lee have shown that a duplex steel with 9.3Mn-5.6Al-0.2C (wt.\%) exhibited an FA-mode of solidification (liquid $\rightarrow$ liquid $+\delta$-ferrite $\rightarrow$ liquid $+\delta$-ferrite $+\gamma$-austenite $\rightarrow \delta$-ferrite $+\gamma$-austenite), while the predicted solidification mode was found to be $\mathrm{F}$ applying the solidification metallurgy of traditional stainless steels. This apparent deviation occurred due to cooling of the liquid metal through a narrow $\delta$-ferrite phase field, directly followed by the dual-phase field of $\delta$-ferrite and $\gamma$-austenite.

The fact that ferritic steels even with a maximum amount of $\mathrm{Al}$ ( 11 wt.\%) exhibited good processability in laboratory hot workability simulations is very promising, as reported by Sunil Kumar et al. However, the presence of $\mathrm{C}$ forms the $\kappa$-carbides that can hinder recrystallization of ferrite and associated grain refinement until very high temperatures when they are dissolved.

Pramanik and Suwas reported on the mechanical properties and microstructure in ferritic $\mathrm{Fe}-\mathrm{Al}$ steels with $\mathrm{Al}$ content up to 9 wt.\%. Significant strengthening (greater than $600 \mathrm{MPa}$ increase in tensile strength with 9 wt.\% $\mathrm{Al}$ ) even in the nearabsence of carbon coupled with good ductility was achieved by high $\mathrm{Al}$ addition, presumably through the solid solution strengthening of $\mathrm{Al}$ in $\mathrm{Fe}$.

The understanding of phase transformations occurring especially in $\mathrm{Mn}$ - and C-containing lowdensity steels is of paramount importance to achieve good mechanical properties. Cheng reported an annealing study on an austenitic steel that underwent spinodal decomposition, precipitation, and cellular transformation. The as-quenched supersaturated austenite transformed to two low-temperature austenite phases through spinodal decomposition, and in one of the spinodal austenite ordered, coherent $\mathrm{L} 1_{2}$-type carbides formed homogeneously. At a relatively higher temperature, precipitation of $\kappa$-carbide and ferrite occurred from austenite, whereas at lower temperatures, precipitation was replaced by different cellular transformations producing lamellar austenite, $\kappa$-carbide, and $\mathrm{M}_{23} \mathrm{C}_{6}$, grown from grain boundary precipitates. It would be interesting to study the effect of these temperature-dependent phase transformations on mechanical properties of different austenite-based alloys.

The evolution of mechanical properties and microstructure in multiphase low-density steels is highly dependent on the alloy chemistry. This has been shown by Hua et al. Excellent elongation (78\%) combined with high tensile strength $(881 \mathrm{MPa})$ was achieved in an Fe-18Mn-10Al-1.2C (wt.\%) triplex steel containing $\kappa$-carbides formed due to high $\mathrm{C}$ content, whereas the alloy with a lower $\mathrm{C}$ content of 0.8 wt.\% exhibited essentially a duplex microstructure and higher strength but lower elongation. Although in both steels planar slip took place, the ductility of the triplex steel was higher owing to the MBIP effect induced in austenite due to the presence of fine $\kappa$-carbides.
Dispersion of ordered phases in disordered solid solution is an effective method for strengthening lowdensity steels albeit with the sacrifice of ductility, which is higher when ordering is avoided. K.-T. Park et al. have shown for an Fe-27Mn-12Al-0.8C (wt.\%) steel that the formation of ordered domains is dependent on post-solutionizing aging temperature. After aging at $500^{\circ} \mathrm{C}$, mainly $\mathrm{D}_{3}$ domains inside ferrite phase were observed as opposed to B2 domains for a $700^{\circ} \mathrm{C}$ aging. On the other hand, the $\kappa$-carbides precipitated only in austenite. The deformation characteristics of the steel involved shearing of $\kappa$-carbides in austenite by planar glide dislocations and interaction of super dislocations in ferrite.

S.-J. Park et al. investigated the influence of second phases on the deformation and fracture behavior of lean-alloyed, multiphase, low-density steels. The study highlighted the importance of mechanical stability and the spherical shape of $\kappa$-carbides, as opposed to lamellar structure, in achieving good mechanical properties. The propensity of Al-rich ferrite to cleavage fracture appears to be a dominating factor in controlling the crack propagation during deformation.

A bulk-scale, high-throughput metallurgical synthesis of austenitic steels by combinatorial method has been presented by Raabe and co-workers. The method may be regarded as a new direction in steel research that would reduce the time and effort for development of new steels. The effect of systematic variation of $\mathrm{Al}$ content (0-11 wt.\%) in $\mathrm{Mn}$ and $\mathrm{C}$ containing steels on their mechanical properties reported in the article adds to the understanding of these low-density steels. The authors also highlighted the susceptibility of the Fe-Mn-Al-C steels to hydrogen embrittlement.

\section{PROSPECTS}

It would appear from the foregoing description that a good deal of fundamentals delving into the understanding of low-density steels have been covered in this special topic. However, aspects relating to the deformation mechanisms in multiphase Fe-Mn-Al-C alloys, formability of ferritic steels, thermodynamics of metallurgical systems pertaining to low-density steels, differences in annealing kinetics of austenite and ferrite in duplex steels, etc., need to be investigated in depth for further understanding of the metallurgy of lowdensity steels. On the implementation and application fronts, the progress is evident from the contributions from the industry. However, processing issues related to castability, rollability, surface oxidation during thermo-mechanical treatment, and coatability in the presence of highalloying additions ( $\mathrm{Mn}$ and $\mathrm{Al}$ ) in these steels need attention and study. Additionally, efforts need to be directed toward improving the Young's modulus of high Al-containing steels so that maximum advantage could be derived from density reduction. 
Future research should also concentrate on the development of lean-alloyed, low-density steels (e.g., low $\mathrm{Mn}$, high $\mathrm{Al}$ containing alloys) that would make these steels less costly, curtailing at least the cost of high Mn addition.

Finally, I wish to record a word of gratitude to all the authors for their excellent contributions that have made the publication on this special topic possible.

The following articles being published under the topic of "Low-Density Steels" provide excellent details and research on the subject. To download any of the papers, follow the url http://link.springer.com/ journal/11837/66/9/page/ 1 to the table of contents page for the September 2014 issue (vol. 66, no. 9):

- "An Overview of Lightweight Ferrous Materials: Strategies and Promises," R. Rana, C. Lahaye, and R.K. Ray

- "Low Density Steels: Complex Metallurgy for Automotive Applications," I. Zuazo, B. Hallstedt, B. Lindahl, M. Selleby, M. Soler, A. Etienne, A. Perlade, D. Hasenpouth, V. Massardier-Jourdan, S. Cazottes, and X. Kleber

- "Microstructural Developments and Tensile Properties of Lean Fe-Mn-Al-C Lightweight Steels," S.S. Sohn, S. Lee, B.-J. Lee, and J.-H. Kwak

- "Review on $\delta$-TRIP Steels with Low Density: The Concept and Current Progress," H.L. Yi

- "High Manganese and Aluminum Steels for the Military and Transportation Industry," L. Bartlett and D. Van Aken

- "Melting, Processing, and Properties of Disordered Fe-Al and Fe-Al-C Based Alloys," V.V. Satya Prasad, S. Khaple, and R.G. Baligidad

- "The Solidification Mode of Fe-Mn-Al-C Lightweight Steel," C.-Y. Lee and Y.-K. Lee

- "Workability Studies on High Al Ferritic Fe-Al-C Alloys," R. Sunil Kumar, U. Prakash, S. K Nath, and R.G. Baligidad

- "Low Density Steels: The Effect of Al Addition on Microstructure and Properties," S. Pramanik and S. Suwas
- "Phase Transformations of an Fe-0.85 C-17.9 Mn7.1 Al Austenitic Steel after Quenching and Annealing," W.-C. Cheng

- "Microstructures and Mechanical Behavior of Fe18Mn-10Al-(0.8-1.2)C Steels," D. Hua, H. Dong, C. Zhihui, and W. Zhiqiang

- "Effects of Heat Treatment on Microstructure and Tensile Properties of a Fe-27Mn-12Al-0.8C Low Density Steel,” K.-T. Park, S.W. Hwang, C.Y. Son, and J.-K. Lee

- "Effect of Second Phase on the Deformation and Fracture Behavior of Multiphase Low-Density Steels,” S.-J. Park, Y.-U. Heo, Y. H. Choi, K. Lee, H.N. Han, and D.-W. Suh

- "Alloy Design, Combinatorial Synthesis, and Microstructure-Property Relations for Low Density Fe-Mn-Al-C Austenitic Steels,” D. Raabe, H. Springer, I. Gutierrez-Urrutia, F. Roters, M. Bausch, J.-B. Seol, M. Koyama, and P.-P. Choi

\section{REFERENCES}

1. aluMatter (European Aluminium Association and MATTER), aluminium.matter.org.uk.

2. R. Rana, Can. Metall. Q. 53, 241 (2014).

3. K. Hill, D. Menk, and A. Cooper, Contribution of the automotive industry to the economics of all fifty states and the United States (Center for Automotive Research (CAR), Ann Arbor, Michigan, April 2010).

4. Regulation (EC) No 443/2009 of the European Parliament and of the Council (April 2009).

5. W. Korter and W. Ton, Arch. Eisenhuettenw. 7, 365 (1933).

6. J.L. Ham and R.E. Carin, Prod. Eng. 52, 59 (1958).

7. U. Prakash, R.A. Buckley, H. Jones, and C.M. Sellars, ISIJ Int. 31, 1113 (1991).

8. I. Baker and P.R. Munroe, Int. Mater. Rev. 42, 181 (1997).

9. C.G. McKamey, J.H. De Van, P.F. Tortorelli, and V.K. Sikka, J. Mater. Res. 6, 1779 (1991).

10. M.A. Van Ende, M. Guo, J. Proost, B. Blanpain, and P. Wollants, ISIJ Int. 51, 27 (2011).

11. M.L. Glenn, S.J. Bullard, D.E. Larson, and S.C. Rhoads, J. Mater. Energy Syst. 7, 75 (1985).

12. A.H. Bott, F.B. Pickering, and G.J. Butterworth, J. Nucl. Mater. 141-143, 1088 (1986).

13. D.-W. Suh and N.J. Kim, Scr. Mater. 68, 337 (2013).

14. R. Rana, C. Liu, and R.K. Ray, Scr. Mater. 68, 354 (2013). 